\title{
Parents Making Meaning of High-Conflict Divorce
}

This article reports on the findings of an empirical study conducted with 25 parents in British Columbia, Canada, who experienced a high-conflict divorce and later came to see the experience as having been transformative despite the difficulties they faced. While considerable research and policy initiatives frame high-conflict divorce as an individual and interpersonal problem, there is less reference to the fact that these disputes occur in a social, political and legal context that also changes over time and across generations. There has been little research examining long-term divorce outcomes, and no research to date examining how mothers and fathers who experienced a high-conflict divorce process overcome their difficulties and make meaning of their experiences retrospectively. This interdisciplinary study starts to fill these gaps. Following an overview of the study findings, the article highlights common themes arising from parents' narratives with a particular focus on agency, voice, and meaning-making across the life course. I argue that by taking a long view of the challenges participants faced, it is possible to move away from decontextualised understandings of high-conflict divorce.

Keywords: high-conflict divorce; parent experiences; meaning-making; agency; voice; transformation

\section{Key Points}

1 Familiarises counsellors with diverse challenges faced by parents in a high-conflict divorce.

2 Draws attention to parents' voices and agency and their role in self-authorisation.

3 Explores how these parents make meaning and change over the life course.

4 Summarises practices that may support clients' transformation over time.

5 Stimulates reflection on professional knowledge construction.

Measured at discreet points in time after separation, an Australian study (Qu, Weston, Moloney, Kaspiew, \& Dunstan, 2014) found that between $10 \%$ and $20 \%$ of separated parents were experiencing significant conflict regarding their children or property. While for most of this group levels of conflict ebb and flow and generally decrease over time, $4-5 \%$ of separated parents remained in conflict over a five-year period. An earlier American study concluded that for a small number of parents, high levels of conflict last throughout children's growing up years (Johnston \& Roseby, 1997).

Most research, policy discussion, and intervention is based on outsider-expert understandings that categorise divorces, as well as parents enmeshed in 'high conflict,' in polarised and individualised terms. Once a 'case' is so categorised, a priori assumptions tend to be made about the feelings, thoughts and actions of the individuals involved. Such understandings form part of the process by which individuals are known and may come to 'know' themselves. This paper situates the study findings within a discussion of the socially constructed nature of 'high conflict' amongst separated parents. Very little is known about how some parents who have gone through a high-conflict divorce resist the influence of dominant social discourses and come to view their difficulties positively as personally transformative. This gap in the literature is significant, given that they are ideal informants for 
policy and practice developments, and further, child outcomes are better if parents adjust positively to divorce (Kelly \& Emery, 2003; Johnston, 1994).

\section{Gender and Agency}

I begin with the proposition that both motherhood and fatherhood are shaped historically, socially, culturally, politically, morally, and legally (Collier, 2005; Miller, 2005; 2011). For this study, I drew on literature that helped me to understand the broader social context that shapes parents' meaning-making and experiences, including how this context can impact on parental conflict. This literature reflects deep divides and intense debate in which gender is often a central focus. For example, there is a tendency among professionals and policymakers as well as the general public to view high-conflict divorce through the lens of gender conflict between individuals (Smart, 2003).

Family law and child welfare discourses also contain inherent contradictions and inaccurate or outdated notions of motherhood, fatherhood, and childhood that have the effect of polarising fathers' and mothers' positions (Collier, 2005). In the interest of eventually mitigating the conflict, it is important to explore how collective meanings shape personal meanings and experiences of conflict in such situations. In seeking to understand and then go beyond these often-polarised discussions, this article focuses on adult development across the life course (Gilleard \& Higgs, 2016; Mayer, 2009).

Agency is a slippery concept, and the way it is defined and operationalised varies considerably both within and across disciplines. I seek to develop an account of agency that considers active processes of self-interpretation yet also accounts for the relational, material, social and discursive effects that may be experienced as a result of divorce. In this research, I define agency as the subjective awareness of one's capacity for creative action. Awareness of this capacity neither obliges an agent to act nor implies free choice. A view of agency that recognises that agency exists amidst conditions of inequality and coercion and does so in ways that intersect with gender, class, race, and other factors (Madhock, Phillips, \& Wilson, 2013) is helpful in this regard.

\section{Researching Meaning-Making}

The qualitative study that underpins this article was undertaken using a social constructionist epistemological framework (Guba \& Lincoln, 1994; Schwandt, 2000) and a relational ontology (see, e.g., Mauthner \& Doucet, 1998). Social constructionists focus on the social processes (rather than the individual cognitive processes) by which individuals make sense of their experience and the social implications of this construction. Berger and Luckmann (1966) note the emergence of 'expert knowledge', which over time is incorporated into social understandings. Through conversation and over time, meanings and subjective reality then become shared to the extent that concepts and understandings of reality are largely taken for granted (Berger \& Luckmann, 1966).

Since researchers who use a social constructionist methodology see the findings of their research as one possible construction among many, they do not present themselves as neutral and their findings as 'truth' (Andrews, 2012). Instead, they seek to have their findings accepted as plausible, based on a convincing argument (Andrews, 2012). 
Three key assumptions underpin the conception and goals of this study, as well as my methodological choices. Together, these assumptions comprise a critical and relational feminist orientation to the research. First, human beings are interdependent and embedded in a complex web of social relationships that involve both responsibilities and care. These relational connections affect how people understand the world and themselves, the centrality of power relations, and the importance of social context. This view also invites an examination of the role of policy in shaping norms and influencing social practices.

Second, while I assume that categories of knowledge and reality are actively constructed in social relationships and through social interactions, I also recognise that power relations influence such constructions. A relational orientation not only requires attention to human interdependence, vulnerability, and caring, but, importantly, also 'enables an understanding of and accounting for how current post-separation norms and discourses gloss over the inequalities-economic and otherwise-that complicate parenting relationships' (Boyd, 2010, p. 152).

Third, I assume that people are located within particular social, economic, cultural, historical, gender, and political contexts and sets of predominant values and norms. What is understood to be a problem relies not only on shared understandings that circulate among members of the 'general public' (i.e., discourses) but also involves those shared among members of particular groups (e.g., professions, academic disciplines, institutions, and activist organisations). However, these groups may have conflicting needs and perspectives.

\section{Research questions}

With this framework in mind, I asked the following two research questions:

1. How do individual mothers and fathers make sense of their high-conflict divorce process?

a) To what extent are their interpretations influenced by social relations and discourses or debates about gender relations and family life?

b) How do collective meanings drawn from extra-legal discourses shape personal meanings and experiences of conflict in such situations and influence the take-up of legal norms?

2. How can high-conflict divorce become transformed into a more positive experience? Specifically, what facilitates this process, what challenges are encountered, and how are they overcome?

\section{Research methods and study group}

I employed a qualitative research design, conducting in-depth semi-structured face-toface interviews with 18 mothers and seven fathers residing in British Columbia, Canada. The criteria for inclusion in the study were that the participant's high-conflict divorce involved disputes concerning children's living arrangements and/or time with children; and that they regarded surviving or navigating the experience of a 'high-conflict' divorce as having changed them in a positive sense.

Prior to recruiting or interviewing participants, I obtained approval from the Research Ethics Board at Simon Fraser University, Canada (2011s0783). I sought consent through telephone pre-screening, as well as formally through written informed consent. Interviews were conducted between 2012 and 2014 and averaged two hours in length. 
Participants were recruited through lawyers, counsellors, mediators, health professionals, and community agencies in three British Columbia cities. I also placed flyers in community centres and libraries. In the final six months of recruitment, I extended recruitment to the entire province, placed classified advertisements in newspapers in three additional communities, offered a financial incentive, and used snowball sampling.

I took an emergent approach to data analysis. This inductive and iterative approach involves allowing insights, meanings, and themes to unfold throughout data generation and analysis (Guba \& Lincoln, 1994). Key themes were summarised within each account in order to locate individual experiences within their social and political context. After examining these individual themes at length, I determined the common themes across interviews. Final data analysis attended to shared meanings and experiences, situating them in practices of knowledge creation that are used by individuals to make meaning of their circumstances. In writing up the study, I employed multiple strategies to protect participants' confidentiality.

The study group was comprised of parents from a broad range of age groups and times since separation. For example, among the seven participants aged in their forties at the time of separation, the number of years since separation ranged from four to 23 . Therefore, some separated and went through legal disputes during their twenties, others more recently and within their forties. The participants ranged from 42-72 years of age. Eight participants had separated in the 1980s, six in the 1990s, and eleven in the 2000s. Of the 25 parents, 18 had at least one very young child who had not yet reached school age at the time of separation. Two participants identified as (second-generation) Chinese-Canadian and one as Latina (born outside Canada). All other participants were Caucasian. In total, eight participants were born outside Canada, most in Europe. All of the relationships with former spouses or partners described in this study were heterosexual and gender normative. None of the participants was a former partner of another participant.

Participants' financial circumstances, level of education, and employment varied significantly over time, particularly among mothers. Similarly, children's living arrangements varied over time, either in response to legal actions and decisions or for other reasons. Approximately half of the parents described significant health issues (physical and/or emotional, short-term and/or prolonged), which they believed were related to the stress of the highconflict divorce. As well, six parents said that their children had been under treatment for mental health issues, with two attributing these issues to post-separation difficulties. Although the other four parents did not see the issues as related, they felt that their difficult situation made it challenging for them to provide a peaceful environment and continuity of care.

\section{Overview of Research Findings}

Three key themes emerged from participant narratives. First, financial and child-related issues were interconnected; second, most participants felt that they were unheard in the legal process and did not receive justice; third, despite the challenges they faced, and in some instances still do face, positive personal change occurs over time when parents are supported with personal, social, and material resources that address their particular needs and challenges.

\section{Financial and child-related issues}


I turn first to the interrelationship of financial and child-related issues. Gendered meanings of money and motherhood or fatherhood were especially evident in participants' accounts. Many mothers and some fathers said that they did not have (or have access to) financial resources on par with the other parent. Since money determines a parent's ability to access the services of lawyers and other professionals, this was seen as the parent with greater material resources having an unfair advantage in the legal process. Ben, for example, said 'basically, if you've got money you're going to win'. When there was the perception of a parent using that to his or her advantage, such as by resisting financial disclosure or child support, the other parent (usually a woman) was likely to see the former spouse as putting him or herself first, rather than the children. Because child arrangements are meant to be about children's 'best interests,' this becomes fertile ground for additional conflicts concerning the care of and time with children.

The majority of study participants had at one time agreed to and engaged in a fairly traditional gendered division of labour and were conscious of normative expectations for mothers and fathers, both of which shaped their decisions before starting a family. As a result, most mothers felt at a disadvantage financially. As well, some mothers had invested heavily in their parenting role and were not always persuaded that it was in the interests of their children for them to enter or soon return to employment. Most of the fathers, however, wanted to take a greater role in childrearing post-separation and to work less, in line with contemporary norms. Those who did so described the shift of both focus and time as changing the meaning of fatherhood for them. At the same time, also in line with dominant notions of masculinity, most of the fathers saw money as linked to their status as men (more than as fathers).

While parents did still exercise agency regarding the balance of employment and childcare post-separation, mothers' found their ability to choose what was best for themselves and their children constrained, both due to their weaker financial position and because shared responsibility post-separation is now the norm in British Columbia (as in many jurisdictions) unless an alternative is otherwise agreed upon or ordered by the courts. Nevertheless, despite the difficulties they encountered (such as non- or underpayment of child support), most struggled on, thus further exercising their agency, to become financially independent. However, for some mothers, this also came with costs to their health and well being and their financial security later in life.

It was found that another way financial and child-related issues were interconnected and interwoven with gendered meanings involves the meaning of shared parenting. Postseparation norms involve the expectation that parents will resolve their disputes out of court and work together in the interests of their children. However, the parents had different understandings of the meaning of sharing, again along gender lines. While mothers had initially subscribed to the ideals of collaboration, unless there was reason to believe otherwise (e.g., domestic violence or incapacity of some sort), they later found that communication was so poor that consensus was almost impossible. Fathers, on the other hand, largely envisioned shared parenting in relation to the structuring of time and preferred to parent autonomously (i.e., the 'parallel parenting' approach), with most seeing their former partner as seeking to control or criticise their parenting rather than as a 'parenting partner.' This interesting finding warrants further exploration. 


\section{The legal process}

The second key theme was that most participants felt unheard in the legal process and felt that the legal system was not just. Before their encounters with the legal system, most participants had an idealistic understanding of what the legal system does or is supposed to do. However, once involved, most reported that they became frustrated, angry, disillusioned, frightened, intimidated, and/or confused, as their experience did not come close to meeting expectations. This is not surprising because when people perceive injustice-for example when they experience the adverse consequences of justiciable problems or believe they have been treated unfairly-they are more likely to develop negative attitudes towards the justice system (Currie, 2007).

Parents extensively described 'unjust' experiences, treatment, or outcomes both within the legal process and by affiliated professionals. Drawing on their own meanings of justice, participants variously described the family law system as unjust, unfair, biased, too complex, and full of loopholes. For example, Lisa said, 'the legal system is not just. It doesn't represent mothers; it doesn't represent people. It represents...statutes and affidavits and knowing the court system but it doesn't actually do anything for the people that are part of that system.'

In addition to perceiving that the system had failed them, participants overwhelmingly found the legal system complex. Legal rules and norms, obscure institutional practices, and 'expert' ways of knowing seemed to predominate over what were seen as essential aspects of a just system: fairness, neutrality, transparency, accountability, and the ability to be heard. Graham put it succinctly: 'The thing about divorce is that nobody is heard. People just want to be heard, really heard.' Generally, when participants spoke about their experience in this regard, they variously described being ignored, silenced, even belittled, and their experiences minimised. Depending on the material and social supports or resources available to them, some persisted or resisted, while others withdrew or gave up on the legal system entirely.

Speaking and being heard was not only understood as an issue of the legal system. Mothers often spoke of voice as a women's issue-a result of social conditioning and the invisibility of their efforts. As Margo put it, 'We're just so, so habituated to [sighs] putting others' needs ahead of ours and it's a real unlearning or relearning.' When her ex-spouse travelled for business during periods when it was his turn to be responsible for their children, she could have used some extra assistance with childcare. She neglected her own needs but did not speak up. In retrospect, she thinks it would have been better if she had, '...because it is hard work to be a full-time single parent...and society doesn't recognise that.'

Over time, and with increased understanding of how family law works, parents engaged with dominant discourses about separated parents, especially those labelled as 'high-conflict couples.' Once categorised as such, these parents are presumed to be incapable of speaking authoritatively about the needs and interests of their children. In response, perhaps to their lack of ability to be 'seen' and heard, and the frustration and sense of powerlessness they felt at the time, parents generated counter-narratives, both to resolve their difficulties and to position themselves once again as good parents (Kaganas \& Day Sclater, 2004). For example, some participants spoke about the 'best interests' of children in authoritative but alternative ways. Sofia felt strongly that it was not in the best interests of her child to be shuffled 'back and forth,' especially when the other parent is abusive and refuses to agree to a regular pattern of parenting time. She said, 'It's not like I'm blaming him, but he didn't want to do what was best, 
right?' Sofia's comment is not only a counter-narrative about her child's best interests but also a response to dominant discourses of the importance of shared parenting and of parents who are in conflict over their children. Here, she reclaims her parental authority as a mother who puts the interests of her child first and indicates that she is a person with agency who can speak for herself authoritatively. According to Somers (1994), people strategically produce counternarratives when they find that their experiences are incongruent with the available socially acceptable narratives about people in their circumstances.

Over time, most participants found innovative and creative ways to be heard. Many engaged in a process of reconstructing their identities as self-authorising; that is, as individuals who speak about their experience and are heard. However, this was not true of all participants, nor was it by any means a finished process.

\section{Positive change over time}

The third key theme to emerge from participant narratives was that of positive change over time. This change was interlinked with what would otherwise be considered normal processes of adult development and was especially apparent when parents had or were able to access needed personal, social, and financial resources. It is important to remember that participants in this study comprised a diverse group in terms of (a) when they separated, (b) where they were in the adult lifespan at the time of the interview, and (c) the circumstances involved. The circumstances of each parent resulted in specific challenges. Nevertheless, parents consistently described a process of adult development that paralleled these challenges.

Seventeen participants described personal development that enabled them to move forward despite the challenges that remained. Some parents engaged in therapy, either individually or in groups, while others turned to coaches or began new careers. Another six parents sought to reform family law or related systems, such as welfare and child protection, hoping to assist others facing similar circumstances. These activities were a way of making meaning and moving forward positively. A small number engaged in both strategies, both as a way to respond to the sense of frustration and injustice they felt and as a way of empowering themselves. Parents' abilities to engage in such strategies were especially facilitated by adequate personal, social, and financial resources. Following a discussion of what participants said helped to support their positive transformation, I will return to discuss adult development over the life course, as described by participants.

\section{What Helped?}

Parents identified crucial supports and resources that helped them not only to navigate the process but also to move forward in their lives. Most frequently described were personal support systems, including family and friends; social support systems (counselling, personal development courses and support groups, personal coaching, community agency programs and services); spiritual practices; and undertaking new challenges to build confidence and resilience (e.g., Toastmasters or rock-climbing). For most participants, these factors, combined with welldeveloped internal resources, helped them navigate the process and ultimately facilitated their transformation. As Jen put it: 
[It was a] combination of friends, spiritual support, um, I think I have...a sense of myself, a trust in myself, in getting through things. I also come from a strong line of women who are very selfsufficient, can be very independent.

While Jen's internal resources assisted her tremendously, this excerpt also suggests that these internal resources were developed relationally, through the scaffolding of generations of strong women within her family. She also described herself as having determination, resourcefulness, a pioneering spirit, and optimism - all qualities typically associated with resilience. Furthermore, Jen is deeply rooted in her community, with many close friends and a sense of 'a village holding' her. This sense of being cared about and social connection was crucial because after losing custody of her children, and with that a real 'loss of identity and mothering role,' she returned to university to become a helping professional.

Thus, Jen's engagement in the community and her strong social network not only developed relationally but resulted in what she described as an expanded sense of mothering. The care that she could not immediately provide for her children was shared with others, such that she was both recipient and provider of care. Jen described spirituality, counselling and personal development, and participation in competitive cycling as further resources in her transformation.

Steve similarly described support from family and friends, strong community connections, and with a broad range of workplace supports including an Employee Assistance Program that provides extensive coverage for counselling, a 'critical incident stress team' that supports employees in both work-related and personal crises, and an ethic of mutual support among fellow employees. Using these resources to deal with 'the emotional part,' Steve described how his behaviour, values, and the meaning of fatherhood changed for him over time to further support his transformation.

Steve and Jen already had, drew on, and further developed both internal resources and social resources, which facilitated their transformation. These two examples highlight a key finding of the study: that participants who were able to access counselling and other supports and also maintain a high level of social and community engagement fared best overall. This finding has important implications for outcomes, yet social resources are not equally distributed. Participants' financial resources are central to their ability to access both legal help and other forms of support that families need and benefit from when they are in crisis: counselling or therapy, for example. While most of the parents had accessed some sort of therapy for their children, especially if there were complex circumstances (e.g., parent or child with health or mental health concerns, abuse, abduction, or addictions), parents that were also able to access counselling for themselves said that what was most helpful was the opportunity to better understand themselves in a safe and supportive relationship. This enabled them to explore new ways of dealing with their difficult circumstances, make meaning of the past, and explore future options.

Counsellors the participants described as most helpful were those who had experienced divorce and the challenges of single parenting, and those with some legal knowledge. Participants said their counsellor helped them to: overcome self-blame and confusion while navigating separation and the many transitions involved (Cindy); understand oneself in the dynamic, set boundaries and express anger (Sheila); address problematic behaviour, including 
lack of emotional availability and anger issues (Steve); navigate through guilt, shame, negative self-judgement and struggles with self-care (Margo); and deal with anger, manage emotions and learn to be assertive in conflict situations (Graham).

Although counselling was highly valued overall, less than half of those interviewed had attended divorce specific counselling or groups, perhaps due to the diversity of their experiences and challenges. Some participants also undertook personal coaching and participated in psycho-educational, self-help, and support groups. However, since legal expenses left many parents without spare funds for such supports, the expense of attending also added to their difficulties.

These findings indicate that a multidisciplinary approach (or 'one stop shop' such as Australia's Family Resource Centres) may be invaluable to parents. Differential access to the courts and other services is an issue in Canada as in many other Western countries. Parents who have a low income, especially when combined with a low educational level and language barriers, have a considerable need for the assistance of professionals with the necessary skills and knowledge. Study participants in situations where the other parent had greater access to funds for litigation found themselves at a particular disadvantage, which added to their perception of injustice. Even middle-income parents struggled to obtain support, especially while disputes were ongoing. Warm referrals within a community of service providers might be especially useful when families are dealing with complex and intersecting problems or have few personal supports.

\section{Adult Development Over the Life Course}

I now turn to a central argument of this paper, which is that recognising that some of the difficulties participants needed to confront and address over time are aspects of normal adult development, enables a shift from viewing high-conflict divorce as indicative of personal or parental pathology, and offers a more constructive way forward. To further this argument, I explore participants' accounts of change from a life course perspective.

The life course perspective assumes that human lives change over a lifetime. Life course development is understood and analysed as the result of cultural frames, social structures, personal characteristics, and individual agency (Mayer, 2009). Human lives are examined across multiple domains and cohorts, and in their collective contexts (e.g., couples and families) (Mayer, 2009). I view life course development as a psychosocial process in that individual trajectories involve both personal agency and social and structural factors. My understandings are also influenced by critiques of individualistic approaches to personal development (e.g., Harris, 2016), which may be used to individualise responsibility for problems that have a structural dimension and thus justify reduced state support for social programs.

Common processes emerged in participants' narratives as central to their transformation, including figuring out the meaning of power and agency, becoming selfauthorising subjects, developing and then practising adult relationship skills (such as effective communication), meaning-making over time, and meaning-making in relation to broader social changes. Retrospectively, the majority realised that their experiences occurred in a specific social, cultural, and historical context. For most, gender norms and family practices are quite different now from what they were then. As they changed individually, as their place in the adult lifespan changed and as social practices changed across generations, parents became less 
invested in gender norms. Indeed, most ultimately questioned the norms that had at one time seemed so natural to them.

The challenges participants described required a rapid acceleration in adult development at the same time as most were dealing with the numerous transitions associated with separation, and often other complex circumstances. Most of the challenges they described, including learning how to communicate effectively, to resolve conflict and set boundaries, and to rethink cultural expectations, especially gendered ones, are key tasks of adult development. Participants described their struggles as an evolutionary process. Indeed, few people enter adulthood with the necessary skills for effective relationships in place.

As adults develop and change, meanings are made and selves are constructed, reconstructed, and transformed, both in relation to divorce and other life experiences. Miller (2011) notes that while dominant discourses of the 'good' father (i.e., involved, employed, partnered, white and heterosexual) are now more visible across most Western societies, discourses of motherhood are both well recognised and morally 'policed.' Some mothers in my study eventually recognised and resisted such discourses and the shame they produced, yet struggled nonetheless.

Margo, for example, spoke at length about how she had internalised norms of motherhood, adult success, and good parenting. She experienced them as 'Caustic! Just harmful and horrible.' For many years she felt that she had failed and let her children down. At one point she even felt suicidal. 'It was about guilt and shame, I...it wasn't that it was too much...well that was part of it but it was mostly because I wasn't measuring up in my own view.' In response to my question about what would have made the process easier, Margo mentioned more counselling and access to legal aid, but even then she was not sure because there was,

'seven, eight years of self-flagellation...that isn't constructive. I don't know how that could have been remedied [sighs] given the people involved and the fact that it was constantly fanned and the whole charge of you bad person, you, you know?'

Although Margo had been separated for 17 years at the time of interview, with 13 of those years very difficult, things had changed in recent years. Not only has she cultivated selfforgiveness and forgiveness toward her former husband, but she believes he has also 'forgiven and matured.' In part because of their child's health challenges, they were now on very different terms. For the past few years 'he's been over for Christmas dinner and, um, we're more than civil, we hug each other and so really has come a long way. But it took 13 years to make that so [laughs].' Margo concluded by saying that although she still judged herself at times, she feels 'good about how things are in my life right now and how I am with my children and how I am in all areas of my life.' As a woman in her 50s who has been through a difficult divorce, she is 'intact as a person, probably better as a person.'

Another mother and a father also described a similar shift occurring after more than 25 years. In all three instances, it was a desire for family harmony amid crisis that prompted the shift, and each recognised that there were limitations as to what could be discussed. Although these situations were not the norm, most parents learned to 'pick [their] battles,' 'take the high-road' and manage their reactions. In addition, most had developed effective 
communication skills that facilitated strong relationships with their children, and in some instances positive new relationships.

\section{Discussion}

Participants in my study navigated a range of complex personal and family circumstances while also making positive changes in their lives. All were aware of common stereotypes of parents enmeshed in a high-conflict divorce and over time resisted or rejected these stereotypes. Still, they felt judged before their circumstances and handling of them were known. Many saw themselves as having done everything possible, often at great personal and financial cost, and as left to 'pick up the pieces.' Participants variously described feeling judged, shamed, boxed in, labelled, and angry in response.

High-conflict divorce is not simply an individual or interpersonal problem. It is a complex process with a diversity of contributing factors and potential paths forward. Former partners may move in and out of conflict, for a broad range of reasons. Hence, using the term 'highconflict' to describe the divorce process rather than 'cases,' couples, or families will remind those in the midst of such a process, as well as those who work with them, that with time, change is indeed possible.

Interestingly, and somewhat paradoxically, my findings suggest that a shift from professional authority and expertise to self-authorisation and personal agency is central to transformation. While this finding may be related to the selection criteria and individuals who participated in the study, it indicates that positive change occurs with meaning-making and with the development of a sense of oneself as a 'knower' with agency.

Family therapists and counsellors can play a key role in clients' self-authorisation, which further promotes agency. For example, many parents in my study were aware of, and highly sensitive to, commonly circulating stereotypes (e.g., about lone fathers as inept, lone mothers as deficient, divorcing mothers as vindictive, 'deadbeat' dads). Once these stereotypes are raised, parents can assess whether their values and experiences fit with such views. If they do not, a counsellor could support the parent to affirm their self-knowledge; that is, to determine what is true about them. The client could then determine whether there are helpful actions they can take, either in responding to others or simply to protect themselves in an emotional or legal sense.

The support of counsellors and therapists across a range of settings plays a crucial role for many parents as they navigate a high-conflict divorce. Counsellors can help by normalising the process and making space for strong feelings to be expressed (Day Sclater, 1997) assisting with broader life changes and reorganisation, as well as offering information and referrals as needed. Counsellors that participants described as most helpful were those able to assist them with complex and interrelated challenges involving the legal process and lone parenting, as well as challenges and changes associated with adulthood and parenthood. These counsellors supported their client constructively and knowledgeably, with a long view of the personal, interpersonal, social, and legal processes at play.

\section{Conclusion}

A key aim in conducting this study was to offer parents who are in the midst of a highconflict divorce and those working with them helpful ideas for a path through the process and 
hope for a positive outcome. Although in many ways the legal process has a life of its own, participants unequivocally told me that having a guide or mentor to support them through the process was or would have been invaluable. To be especially helpful, the guide needs at least a basic understanding of legal interventions, awareness of the difficulties parents may face in accessing legal services, knowledge about the personal and emotional process of ending a relationship when children are involved, understanding of parenting challenges, and much more.

My study shows that for many individuals, these legally framed conflicts may shape their adult lives and parenting. At the same time, meaning-making is ongoing across the adult life course - a fact that is currently missing from dominant understandings of high-conflict divorce and the policies and practices that are intended to address it. My research shows that parents may have different needs, struggles, and perceptions at different times. While all participants felt that the experience had changed them in a positive sense, many also indicated that some challenges remained. Overall, resilience and, ultimately, transformation as a result of the experience of a high-conflict divorce are not simply connected to individual efforts and processes but are largely linked to one's resources and the broader social context.

Attention to stereotypes alone will not end post separation conflicts. Social and labour force policies - such as parental leave and the availability of quality affordable childcare - that support families and promote real options for both parents need to sit beside timely and effective legal practices and interventions. That said, the findings of this study do challenge the more individualised and narrowly focused constructions of 'high conflict' between separated parents. They offer ideas for supporting positive personal change at times when the road ahead appears to offer no alternatives.

\section{References}

Andrews, T. (2012). What is social constructionism? Grounded Theory Review, 11(1), 39-46.

Berger, P., \& Luckmann, T. (1966). The social construction of reality: A treatise in the sociology of knowledge. New York: Anchor Press.

Boyd, S. B. (2010). Autonomy for mothers? Relational theory and parenting apart. Feminist Legal Studies, 18(2), 137-158.

Collier, R. (2005). Fathers 4 Justice: Law and the new politics of fatherhood. Child and Family Law Quarterly, 17(4), 1-29.

Currie, A. (2007). The legal problems of everyday life: The nature, extent and consequences of justiciable problems experienced by Canadians. Ottawa: Department of Justice. Retrieved from www.justice.gc.ca/eng/rp-pr/csj-sjc/jsp-sjp/rr07 la1-rr07 aj1/rr07 la1.pdf

Day Sclater, S. (1997). Narratives of divorce. Journal of Social Welfare and Family Law, 19(4), 423-441. 
Day Sclater, S. (1999). Divorce: A psychosocial study. Aldershot, UK: Ashgate.

Gilleard, C., \& Higgs, P. (2016). Connecting life span development with the sociology of the life course: A new direction. Sociology, 50(2), 301-315.

Guba, E., \& Lincoln, Y. (1994). Competing paradigms in qualitative research. In N. K. Denzin \& Y. S. Lincoln (Eds.), Handbook of qualitative research (pp. 105-117). Thousand Oaks, CA: Sage.

Harris, A. (2016). Care and danger: Feminism and therapy culture. Studies in Law, Politics, and Society, 69, 113-140.

Johnston, J. (1994). Children and divorce. The Future of Children, 4(1), 165-182.

Johnston, J., \& Roseby, V. (1997). In the name of the child: A developmental approach to understanding and helping children of conflicted and violent divorce. New York: Free Press.

Kaganas, F., \& Day Sclater, S. (2004). Contact disputes: Narrative constructions of 'good' parents. Feminist Legal Studies, 12(1), 1-27.

Kelly, J., \& Emery, R. (2003). Children's adjustment following divorce: Risk and resilience perspectives. Family Relations, 52(4), 352-362.

Madhock, S., Phillips, A., \& Wilson, K. (2013). Gender, agency, and coercion. Basingstoke, UK: Palgrave MacMillan.

Mauthner, N., \& Doucet, A. (1998). Reflections on a voice-centred relational method of data analysis: Analysing maternal and domestic voices. In J. Ribbens \& R. Edwards (Eds.), Feminist dilemmas in qualitative research: Private lives and public texts (pp. 119-144). London: Sage.

Mayer, K. (2009). New directions in life course research. Annual Review of Sociology, 35(1), 413-433.

Miller, T. (2005). Making sense of motherhood: A narrative approach. Cambridge, UK: Cambridge University Press.

Miller, T. (2011). Making sense of fatherhood: Gender, caring and work. Cambridge: Cambridge University Press.

Qu, L., Weston, R., Moloney, L., Kaspiew, R., \& Dunstan, J. (2014). Post-separation parenting, property and relationship dynamics after five years. Canberra, Australia: Attorney-General's Department. Melbourne: Australian Institute of Family Studies. 
Schwandt, T. (2000). Three epistemological stances for qualitative inquiry: Interpretivism, hermeneutic, and social constructionism. In N. Denzin \& Y. Lincoln (Eds.), Handbook of qualitative research (2 ed., pp. 189-213). New York: Sage.

Smart, C. (2003). Towards an understanding of family change: Gender conflict and children's citizenship. Australian Journal of Family Law, 17(1), 1-17.

Somers, M. (1994). The narrative constitution of identity: A relational and network approach. Theory and Society, 23(5), 605-649. 